\title{
Oligofructose-Enriched Inulin
}

National Cancer Institute

\section{Source}

National Cancer Institute. Oligofructose-Enriched Inulin. NCI Thesaurus. Code C61598.

A mixture of non-digestible carbohydrates, containing the fermentable plant fructans oligosaccharide and inulin, with potential prebiotic activity. Resisting hydrolysis by intestinal digestive enzymes, inulin and oligofructose serve as growth media and energy substrates for bifidobacteria in the colon; beneficial colonic commensal bacteria such as bifidobacteria may inhibit the colonization of the intestine by pathogenic bacteria and have been implicated to inhibit colon carcinogenesis. Olig ofructose-enriched inulin may be administered in combination with probiotic bifidobacteria. In addition, this agent may promote the absorption of calcium and magnesium from the gastrointestinal tract. 